\title{
ENTRE MEMÓRIAS E HISTÓRIAS: a trajetória de formação e atuação profissional de uma professora acreana
}

\author{
BETWEEN MEMORIES AND STORIES: \\ the trajectory of training and professional performance \\ of an Acre teacher
}

ENTRE MEMORIAS Y HISTORIAS: la trayectoria de capacitación y desempeño profesional de un maestro de Acre

\author{
Mark Clark Assen de Carvalho (iDa \\ ARNALDO VIEIRA DE MoRAIS (iDo \\ AdÃo Rogério XaVier Silva \\ JOSÉ PEREIRA FLORES (iD)
}

\section{Resumo}

Este trabalho, organizado a partir de um relato autobiográfico, aborda questões referentes ao processo de formação e desenvolvimento profissional no magistério, destacando a trajetória de uma professora acreana que atuou na rede pública de ensino no município de Xapuri-AC, prestando inúmeras contribuições ao desenvolvimento da

\footnotetext{
a Universidade Federal do Acre (UFAC), Rio Branco, AC, BRASIL. Doutor em Educação, e-mail: markassen@yahoo.com.br. https://orcid.org/0000-0003-3638-9719

b Universidade Federal do Acre (UFAC), Rio Branco, AC, BRASIL. Licenciado em Pedagogia, email: vdmorais@hotmsil.com. https://orcid.org/0000-0003-1409-7299

c Universidade Federal do Acre (UFAC), Rio Branco, AC, BRASIL. Mestre em Educação, e-mail: adaorxs@gmail.com. https://orcid.org/0000-0003-0277-3392

d Universidade Federal do Acre (UFAC), Rio Branco, AC, BRASIL. Licenciado em Pedagogia, email: pereiraxap@hotmsil.com. https://orcid.org/0000-0002-4128-4682
}

140 Rev. Caminhos da Educação: diálogos, culturas e diversidades, Teresina, v. 2, n. 2, p.140-160, mai./ago. 2020 
educação pública escolar da Cidade. Tem como objetivo, portanto, apresentar, descrever e analisar a vida, a formação e a carreira dessa professora que veio a se constituir em uma das mais importantes profissionais da educação municipal e uma referência para a educação de Xapuri, interior do Estado do Acre, terra do ambientalista Chico Mendes. Para compreendermos a tessitura da constituição profissional e determinadas questões relacionadas ao modo como a professora foi constituindo-se na profissão e construindo sua identidade profissional recorremos às contribuições de autores como Tardif (2004 e 2011), Nóvoa (1991, 1992, 1994, 2007), Perrenoud (1993), Louro (2008) dentre outros, que foram chamados para a fundamentação o diálogo com os dados extraídos das conversas com a professora e seus relatos profissionais, as fontes documentais cedidas pela professora pesquisada, dentre aquelas que ainda constam em seu acervo particular, além de documentos oficiais, como leis, decretos, resoluções e portarias que indicam questões sobre o magistério acreano e o percurso de formação, atuação e desenvolvimento profissional da professora que inspira o estudo. A realização desse estudo possibilitou-nos concluir que sua formação profissional se deu entrelaçada aos diferentes momentos e contextos vivenciados ao longo de seu percurso profissional, condição esta que lhe permitiu experiências pessoais e profissionais que contribuíram de forma indelével para compor seu repertório de conhecimentos, permitindo-lhes mobilizar diferentes saberes em seu contexto de atuação e de inserção no ofício de ensinar.

Palavras-chave: Relato autobiográfico; Profissão de Professora, Desenvolvimento Profissional no Magistério da Educação Básica.

\section{Abstract}

This work, based on an autobiographical report, addresses issues related to the process of training and professional development in the teaching profession, highlighting the trajectory of an Acre teacher who worked in the municipality of Xapuri-AC and who made numerous contributions to the development of school education in the City. Therefore, it aims to present, describe and analyze the life and career of this public teaching professional who stood out as one of the most important professionals in municipal education and a reference for education in the Municipality of Xapuri, in the interior of the State of Acre. To understand the fabric of the professional constitution and certain issues related to the way the teacher is constituted in the profession and building her professional identity, we resort to the contributions of authors such as Tardif (2004 and 2011), Nóvoa (1991, 1992, 1994, 2007), Perrenoud (1993), Louro (2008) among others, who were called for the reasoning and dialogue with the data extracted from the conversations with the interviewee and her professional reports, the documentary sources provided by the researched teacher among those that are still in her private collection, in addition to official documents, such as laws, decrees, resolutions and ordinances that indicate questions about the Acre teaching profession and the training, performance and professional development of the teacher who inspires the study. The realization of this study allowed us to conclude that the teacher's education was intertwined with the different moments and contexts experienced by her throughout her professional career, a condition that allowed her personal and professional experiences that contributed in an indelible way to compose her repertoire of knowledge, allowing

Rev. Caminhos da Educação: diálogos, culturas e diversidades, Teresina, v. 2, n. 2, p.140-160, mai./ago. 2020 
them to mobilize different knowledge in their context of performance and insertion in the teaching profession.

Keywords: Autobiographical report; Profession of Teacher, Professional Development in the Teaching of Basic Education.

\section{Resumen}

Este trabajo, basado en un informe autobiográfico, aborda cuestiones relacionadas con el proceso de capacitación y desarrollo profesional en la profesión docente, destacando la trayectoria de un maestro de Acre que trabajó en el municipio de Xapuri-AC y que realizó numerosas contribuciones al desarrollo de la educación escolar en la ciudad. Por lo tanto, tiene como objetivo presentar, describir y analizar la vida y la carrera de este profesional de la enseñanza pública que se destacó como uno de los profesionales más importantes en educación municipal y una referencia para la educación en el Municipio de Xapuri, en el interior del Estado de Acre. Para comprender el tejido de la constitución profesional y ciertos temas relacionados con la forma en que el maestro se constituye en la profesión y la construcción de su identidad profesional, recurrimos a las contribuciones de autores como Tardif (2004 y 2011), Nóvoa (1991, 1992, 1994, 2007) , Perrenoud (1993), Louro (2008) entre otros, quienes fueron llamados para razonar y dialogar con los datos extraídos de las conversaciones con la entrevistada y sus informes profesionales, las fuentes documentales proporcionadas por la maestra investigada entre las que aún están en su colección privada, además de documentos oficiales, como leyes, decretos, resoluciones y ordenanzas que indican preguntas sobre la profesión docente de Acre y la capacitación, el desempeño y el desarrollo profesional del maestro que inspira el estudio. La realización de este estudio nos permitió concluir que la educación de la maestra estaba entrelazada con los diferentes momentos y contextos experimentados por ella a lo largo de su carrera profesional, una condición que permitió sus experiencias personales y profesionales que contribuyeron de manera indeleble a componer su repertorio de conocimiento, lo que les permite movilizar diferentes conocimientos en su contexto de desempeño e inserción en la profesión docente.

Palabras clave: Informe autobiográfico; Profesión de Docente, Desarrollo Profesional en la Enseñanza de la Educación Básica.

\section{Introdução}

A ideia do estudo se insere no campo da formação de professores no sentido de investigar, a partir do relato autobiográfico, como se dá o processo de constituição do "ser professora", orientando-se na direção de ressaltar a própria história de um sujeito ao mesmo tempo singular e plural, cuja trajetória é narrada a partir de suas

Rev. Caminhos da Educação: diálogos, culturas e diversidades, Teresina, v. 2, n. 2, p.140-160, mai./ago. 2020 
vivências e experiências como educadora em um município do interior do Estado do Acre, a cidade de Xapuri, terra do líder seringueiro Chico Mendes.

Para tanto, o estudo se centra na recuperação de alguns dos momentos marcantes da vida e da carreira de uma professional do magistério público que iniciou como professora primária e adquiriu notoriedade, destacando-se como uma das mais importantes profissionais do magistério público e uma referência no processo educacional do Município de Xapuri. Estamos a nos referir, com a devida licença, à Professora Raimunda Euri Gomes Figueiredo que, durantes décadas, se firmou como uma referência e uma das protagonistas principais da história da educação do município.

Partindo de uma perspectiva sócio histórica e autobiográfica o estudo se volta para a identificação e recuperação do percurso formativo dessa profissional, perpassando por alguns momentos que marcam de forma decisiva sua trajetória e atuação profissional, trazendo à tona sua história de vida, mesclando elementos da formação e de atuação profissional, além ressaltar alguns traços de suas práticas pedagógicas e experiências acumuladas ao longo de 32 anos de exercício profissional como professora dos antigos quadros da União, período que remonta ao Acre Território Federal seguido, posteriormente, de aprovação em concurso público para professora da rede pública estadual até o período de sua aposentadoria no ano de 1996.

Assim sendo, nos apoiaremos nas reflexões desenvolvidas por Nóvoa (2007), Louro (2007), Perrenoud (1993) e Tardif (2002) que abordam aspectos sobre a formação de professores, como se dá o processo de desenvolvimento profissional e suas práticas pedagógicas articuladas às suas histórias vida pessoal e profissional, será possível a análise de como a professora vai se constituindo ao longo de sua carreira e as diferentes dimensões que margeiam esse percurso de formação e desenvolvimento profissional.

Recorremos a Nóvoa (2007) para procurarmos estabelecer a relação entre a profissionalização do professor, a construção de sua identidade e história de vida. O referido autor nos auxilia a pensar que a partir de uma retrospectiva histórica é

Rev. Caminhos da Educação: diálogos, culturas e diversidades, Teresina, v. 2, n. 2, p.140-160, mai./ago. 2020 
possível mostrar que as tentativas de racionalização do ensino impuseram a separação entre o eu pessoal e eu profissional do professor.

Trouxemos também como base e suporte de análise os estudos de Louro (2007), que mostra as diferenças que eram impostas pela sociedade com relação ao homem e a mulher. A educação a ela imposta. As concepções tradicionais de postura da mulher. As lutas destas em busca do seu espaço. A conquista do magistério.

Outra referência que nos auxilia na reconstrução ou da contação da história de vida da professora objeto do presente estudo é Tardif (2002) que trata das questões do desenvolvimento pessoal e profissional e os efeitos que podem causar na formação docente, fornecendo os conhecimentos teóricos e técnicos no decorrer da formação e inserção no campo profissional.

A pesquisa bibliográfica, indispensável para a realização de estudos históricos, nos forneceu os subsídios necessários para compreendermos questões relacionadas ao modo de como a professora se constitui ao longo da carreira profissional e suas práticas adotadas no âmbito escolar. Além disso, recorremos à pesquisa documental, porque parte de uma análise de documentos ocorrida de uma investigação ordenada que permitiu-nos uma organização de dados relevantes sobre o tema. (GIL 2002)

Realizamos uma entrevista semiestruturada com questões que abordavam a trajetória de formação e de profissão da professora. A entrevista se deu em dois momentos: no primeiro, realizamos uma conversa informal, na qual a entrevistada falou-nos de maneira geral sobre sua trajetória de vida e atuação profissional desde quando ingressou na escola normal até sua graduação em Letras pela Universidade Federal do Acre/UFAC e, no segundo momento, através de um questionário préestabelecido com um roteiro de questões específicas fizemos a entrevista, a qual devidamente consentida pela professora foi registrada, gravada e, posteriormente, degravada respeitando-se fielmente o conteúdo da fala.

A pesquisa documental se deu por meio da análise dos documentos fornecidos pela professora através do quais podemos constatar sua atuação profissional e formação pessoal e procedemos o seu percurso de atuação em uma perspectiva temporal.

Rev. Caminhos da Educação: diálogos, culturas e diversidades, Teresina, v. 2, n. 2, p.140-160, mai./ago. 2020 


\title{
Os caminhos do magistério em Xapuri: o fazer-se professora
}

A considerar a formação política do município de Xapuri pode-se dizer que, em plena década de 1940, período em que o município era comandado por "coronéis de barranco", homens que mandavam na região e ditavam as regras e delegavam as funções em seus seringais, onde as mulheres, sequer, tinham alguma expectativa de atuação profissional e de desenvolvimento na carreira, a professora cuja história é aqui tratada pode ser reconhecida e identificada como uma profissional de vanguarda, precursora, uma pioneira que ajudou quebrar algumas barreiras impostas pelo sistema local, escrevendo seu nome na história da educação xapuriense.

A partir da afirmação anterior, podemos dizer que o processo de formação do(a) professor(a) não está baseado somente nas estratégias de ensino proposto pela instituição escolar. Todo(a) prfessor(a) precisa refletir sobre sua ação pedagógica, trazendo consigo as experiências de suas relações com as demais esferas da sociedade para que essas sejam transformadas em práticas pedagógicas que vão ao longo do tempo servindo de referência e base para a constituição de nossa identidade profissional.

\begin{abstract}
A formação não se constrói por acumulação (de cursos, de conhecimentos ou de técnicas), mas assim através de um trabalho de reflexibilidade crítica sobre as práticas e de reconstrução permanente de uma identidade pessoal [...] O processo de formação está dependente de percursos educativos... O processo de formação alimenta-se de modelos educativos, mas asfixia quando se torna demasiado "educador". A formação vai e vem, avança e recua, construindo-se num processo de relação ao saber e ao conhecimento. (NÓVOA 1994, p. 03).
\end{abstract}

Baseados nesse pensamento encontramos referências para definimos o foco da escritura do texto: a vida profissional de uma das professoras normalistas, egressa do antigo Colégio Divina Providência de Xapuri buscando identificar, descrever e analisar a história de vida, o percurso de formação e desenvolvimento profissional de um sujeito singular no cenário educacional da cidade de Xapuri, oportunidade em destacaremos questões relativas à formação, carreira e o processo de desenvolvimento profissional no Magistério, procurando compor uma intersecção com a trajetória

Rev. Caminhos da Educação: diálogos, culturas e diversidades, Teresina, v. 2, n. 2, p.140-160, mai./ago. 2020 
profissional da professora Raimunda Euri Gomes Figueiredo, suas experiências, práticas e atuação profissional como professora e gestora em várias instituições escolares de Xapuri.

Fundamentamos nossas reflexões e análises sobre ao processo de formação, desenvolvimento na carreira profissional do magistério nas referências de Nóvoa (2007) e Pimenta (2000), que estabelecem a relação entre formação docente, profissionalização do professor e a construção de identidade e sua história de vida. Nóvoa (1991) também nos auxilia nessa reflexão quando assinala que a prática pedagógica em uma perspectiva reflexiva, através da investigação da ação do professor e sua formação profissional, valorizando os saberes e valores trazidos pelos professores, ou seja, daquilo que os professores já são portadores, sobre as percepções do seu fazer pedagógico.

Baseamo-nos também nas perspectivas de Tardif (2004; 2011) quando este destaca que os saberes sob sua égide acontecem singularmente de forma individual, porem são expandidos e legitimados por meio da interação social do professor com a comunidade, a família e as experiências com seus colegas de trabalho. Através desse processo surge o reconhecimento de saberes voltados aos profissionais do magistério e não somente aqueles saberes aplicados na sala de aula.

Por seu turno, as análises de Perrenoud (1993, p. 178) mostram-nos que dominar e compreender os saberes na essência é fundamental, porém, é preciso também mobilizá-los nas competências e esclarece "que as competências permitem articular constantemente a análise e a ação, a razão e os valores, as finalidades e os constrangimentos da situação”.

As alusões aos autores de referência nesse campo contribuem, então, para que possamos pôr em relevo o fato de que a ação do(a) professor(a) é determinante no contexto educacional. Dessa forma, faz-se necessário que o profissional em educação esteja consciente do seu papel para assim buscar qualificar-se e desenvolver-se profissionalmente frente aos muitos desafios que à educação escolar pública impõe.

Em relação à formação dos professores, a partir da análise da prática pedagógica, Pimenta (1999) identifica o aparecimento da questão dos saberes como um dos aspectos considerados nos estudos sobre identidade da profissão. A autora

Rev. Caminhos da Educação: diálogos, culturas e diversidades, Teresina, v. 2, n. 2, p.140-160, mai./ago. 2020 
parte da premissa de que essa identidade é construída a partir da significação social da profissão; da revisão constante dos significados sociais da profissão; da revisão das tradições, e também da reafirmação das práticas consagradas culturalmente e que permanecem significativas. Essas práticas resistem às inovações porque estão prenhes de saberes válidos às necessidades da realidade. (CF. PIMENTA, 1999, p. 19).

Neste sentido, Pimenta (1999) enfatiza que o professor está em constante processo de formação e que os saberes adquiridos em sua formação inicial precisam sofrer um choque com os vivenciados em seu cotidiano os quais irão lhes permitir fazer uma reflexão sobre sua prática. Dessa forma, essa reflexão permitirá que o professor se desenvolva no âmbito pessoal e profissional para melhorar sua prática profissional e poder intervir e inovar na forma de ensinar, ressignificando suas próprias práticas.

Ao se discutir trajetórias de professoras, percebemos que estas foram se constituindo cotidianamente por meio de experiências vividas dentro e fora das instituições escolares. E para tirar o mito de que pra ser professor é preciso nascer com um dom ou simplesmente ter vocação ou ainda precisa gostar de criança é uma inverdade, visto que muitas escolheram serem professoras por falta de condições financeiras ou por não terem outra opção e ainda existem aquelas que são por gostar da profissão.

De acordo com Nóvoa (1992, p. 16):

A identidade não é um dado adquirido, não é uma propriedade, não é produto. A identidade é um lugar de lutas e conflitos, é um espaço de construção de maneiras de ser e estar na profissão. A construção de identidades sempre passou por um processo complexo, portanto cada um se apropria dele levando em conta o sentido da sua história pessoal e profissional. "É um processo que necessita de tempo". Um tempo para fazer identidades, para acomodar inovações, para assimilar mudanças.

O desenvolvimento profissional docente para Fiorentini (2008) é compreendido como um "processo contínuo que tem início antes de ingressar na licenciatura, estende-se ao longo de toda sua vida profissional e acontece nos múltiplos espaços e momentos da vida de cada um, envolvendo aspectos pessoais, familiares, institucionais e socioculturais. (FIORENTINI 2008, p. 4-5). O autor enfatiza que para tornar-se professor é necessário que aconteça um envolvimento em

Rev. Caminhos da Educação: diálogos, culturas e diversidades, Teresina, v. 2, n. 2, p.140-160, mai./ago. 2020 
todas as áreas da sociedade, cada uma delas fazendo com que o profissional adquira experiência para usar no convívio escolar e em sala de aula.

Segundo Nóvoa (2009, p. 42) "o que confere significado ao desenvolvimento profissional do professor é a reflexão coletiva, que "através dos movimentos pedagógicos ou das comunidades de prática, reforça-se um sentimento de pertença e de identidade profissional". Dessa forma, é importante considerar que o desenvolvimento profissional docente ocorre nas dimensões individual e coletiva, e é a dimensão coletiva que certifica ou identifica a que categoria profissional ele pertence.

Enfim, percebemos que a formação profissional se dá, nos diversos segmentos da sociedade uma vez que o profissional em educação traz consigo marcas de suas experiências vividas, dando suporte para desenvolver de forma individual e coletiva conhecimentos, saberes e práticas que irão compor o repertório dos conhecimentos que o docente mobiliza quando de sua atuação e inserção no oficio de ensinar.

Postas estas considerações cumpre perguntar então quem é a professora Raimunda Euri Gomes Figueiredo? Nasceu em 18 de outubro de 1930, filha de Eurico Gomes Fonseca e Aurelina Pismel Fonseca, nasceu em Xapuri-Ac, mãe de 6 filhos, viúva de Júlio Dias Figueiredo, professora reconhecida e respeitada pela população xapuriense. Aos nove anos de idade veio do seringal com seu pai Eurico Gomes Fonseca, dando início em seu percurso de vida escolar no Colégio das Freiras de Xapuri. Através de muitas lutas e em cumprimento ao rigor da educação católica ofertada em colégios de freiras e padres, conseguiu concluir seus estudos iniciais no ano de 1942, no Colégio Divina Providência.

Figura 1 - Certificado do Curso Primário

Rev. Caminhos da Educação: diálogos, culturas e diversidades, Teresina, v. 2, n. 2, p.140-160, mai./ago. 2020 


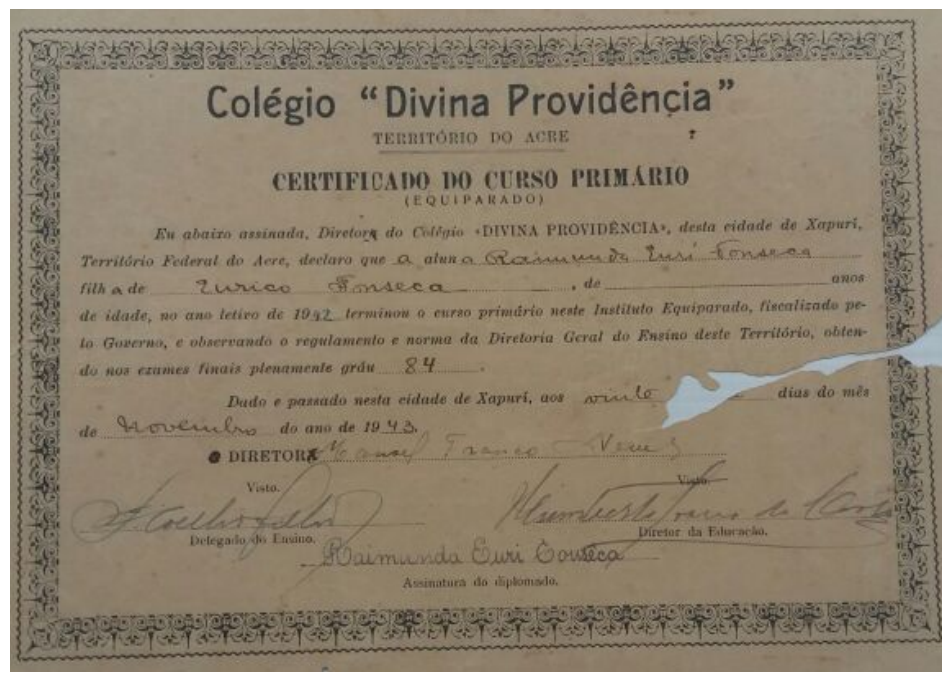

Fonte: Arquivo pessoal da professora.

No ano de 1947 foi nomeada para o Quadro de Professores da Secretaria de Educação e Cultura do Território Federal do Acre, permanecendo até o ano de 1982, tendo optado por manter o vínculo no extinto quadro dos professores da União por conta do Contrato Federal. Segundo nos relatou isso aconteceu por que não tinha comprovação documental na época, não eram expedidos contracheques e por esse motivo escolheu o contrato federal até mesmo por questões salariais. Assim sendo, e por ja ter experiência na escola normal, foi assinado, em 1952, um Decreto que a nomeava como professora do antigo Território Federal, como comprovado na imagem abaixo:

Figura 2 - Nomeação para o cargo de professora do Território do Acre

Rev. Caminhos da Educação: diálogos, culturas e diversidades, Teresina, v. 2, n. 2, p.140-160, mai./ago. 2020 


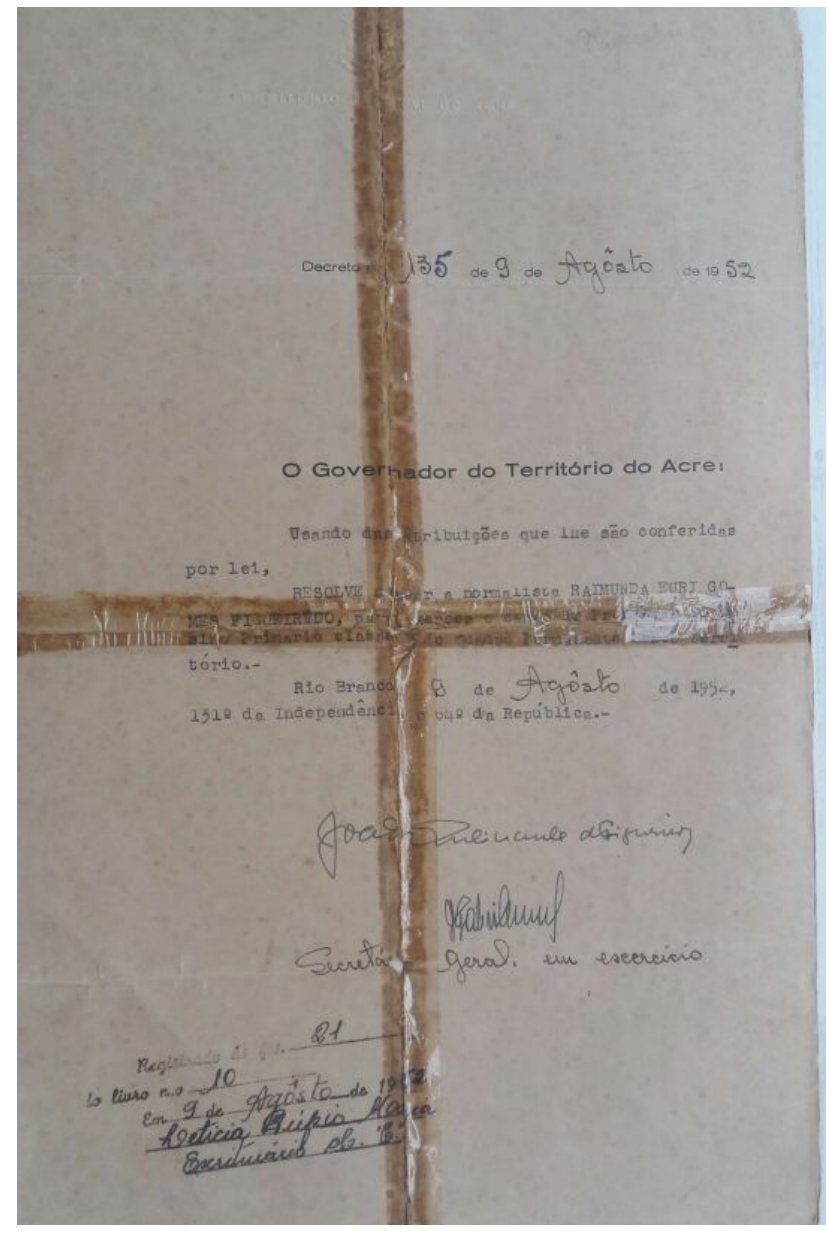

Fonte: Arquivo pessoal da professora.

Mais tarde, em 1967, com o apoio do então Prefeito Municipal, Júlio Dias Figueiredo, esposo da Professora Euri Figueiredo, e junto a outros professores foi fundada a Escola Anthero Soares Bezerra, que atendia uma reivindicação de muitos jovens e adultos que trabalhavam durante o dia e só podiam estudar à noite. Vale destacar é que se tratava da primeira dama da cidade, que poderia ocupar um cargo elevado na administração municipal, mas nem por isso deixou que a vaidade tomasse conta de si e abraçou a luta em favor daqueles que não tiveram oportunidade de estudar.

No que se refere à comprovação via documentação, somente consta uma fotografia da Ata da Reunião Extraordinária para Eleição da Diretoria Provisória do Ginásio Anthero Soares Bezerra, abaixo disposto:

Figura 3 - Ata da reunião extraordinária para a direção da diretoria provisória do Ginásio Anthero Soares Bezerra

Rev. Caminhos da Educação: diálogos, culturas e diversidades, Teresina, v. 2, n. 2, p.140-160, mai./ago. 2020 


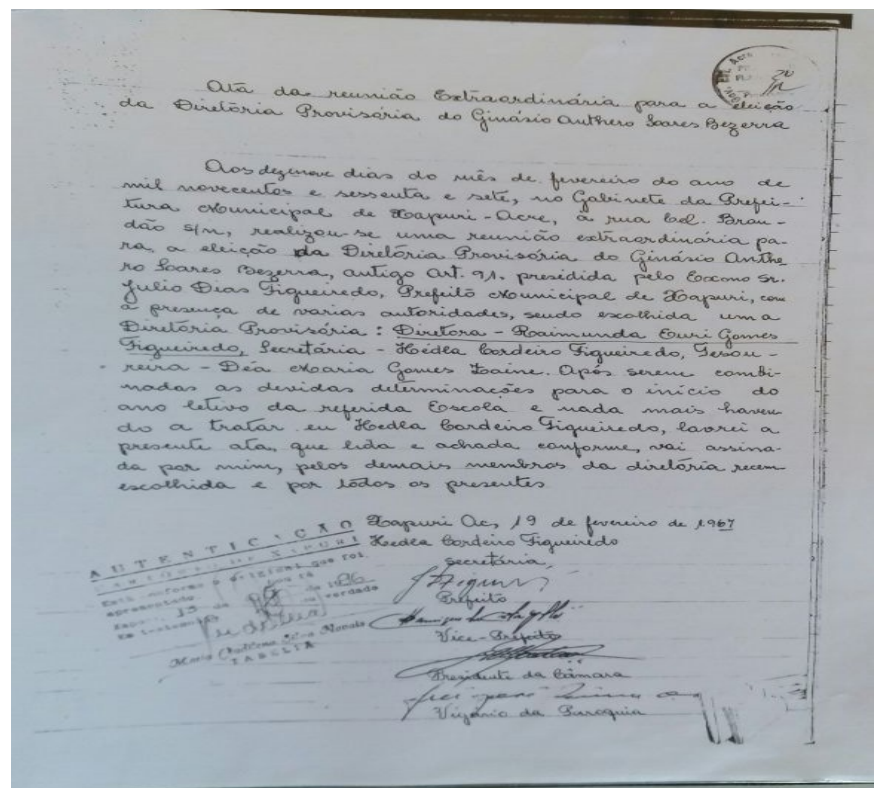

Fonte: Arquivo pessoal da professora.

Esta escola funcionou por um ano somente com professores em situação de voluntariado. Só a partir de 1968 a escola foi devidamente reconhecida pelo Governo do Estado do Acre, passando a via a ter corpo administrativo e docente formado, época em que já contava com cerca de 100 alunos matriculados.

A professora Euri Figueiredo Cursou o $2^{\circ}$ Grau na Escola Normal Padre Felipe Galerani, instituição essa que lhe formou e lhe concedeu à oportunidade ímpar de vir a exercer o magistério. O referido diploma segundo a professora foi perdido durante uma das maiores alagações que atingiu o município de Xapuri no ano de 2015, seu acervo foi em boa parte deteriorado e perdido.

Em 1973 prestou exame de vestibular e iniciou o Curso de Letras/Licenciatura Curta na Universidade Federal do Acre/UFAC, em Regime Parcelado. Este curso foi ofertado em três etapas, preenchendo os períodos de Férias Escolares, sendo que em 1975 concluiu o curso de Letras e continuou a lecionar a disciplina de Português nas $7^{\mathrm{a}}$ e $8^{\circ}$ séries (atualmente $8^{\circ}$ e $9^{\circ}$ ano) nas escolas locais, Língua Portuguesa e Literatura Brasileira no $2^{\circ}$ grau.

Fez o Curso de Licenciatura Curta em Letras Português em uma época em que os professores tinham que se deslocar e passar os três primeiros meses do ano estudando em Rio Branco, visto que o curso de licenciatura oferecido era realizado em regime parcelado e as dificuldades da época eram extremas, pois segundo relata a

Rev. Caminhos da Educação: diálogos, culturas e diversidades, Teresina, v. 2, n. 2, p.140-160, mai./ago. 2020 
professora, "além de deixar sua família e se deslocar para capital a ajuda de custo não era suficiente para suas despesas".

Figura 4 - Diploma de Licenciatura Curta em Letras

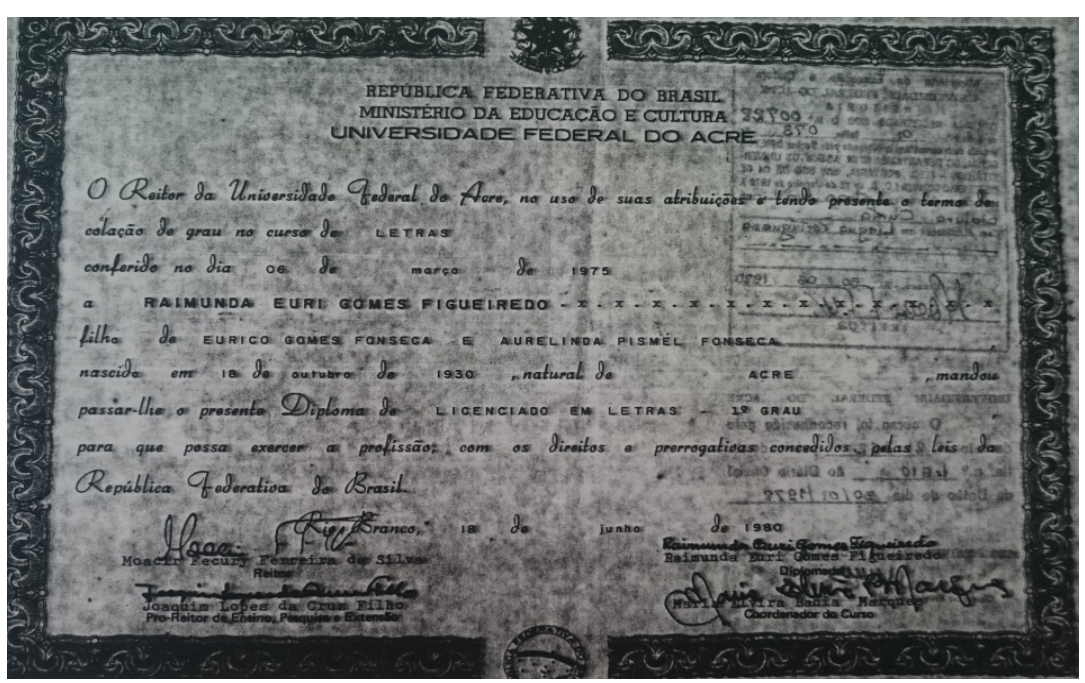

Fonte: Arquivo pessoal da professora.

No período entre os anos de 1981 a 1983 a Universidade Federal do Acre em conjunto com a SEEC, implementaram nos meses de janeiro, fevereiro e julho cursos de Licenciatura de $1^{\circ}$ grau em Regime Parcelado, que foram oferecidos na cidade de Cruzeiro do Sul e Xapuri e, na ocasião, a Professora Euri Figueiredo foi convidada para exercer a função de Subcoordenadora do Núcleo da UFAC em Xapuri como demonstra o documento apresentado a seguir:

Figura 5 - Portaria de Subcoordenadora no núcleo da UFAC de Xapuri

Rev. Caminhos da Educação: diálogos, culturas e diversidades, Teresina, v. 2, n. 2, p.140-160, mai./ago. 2020 


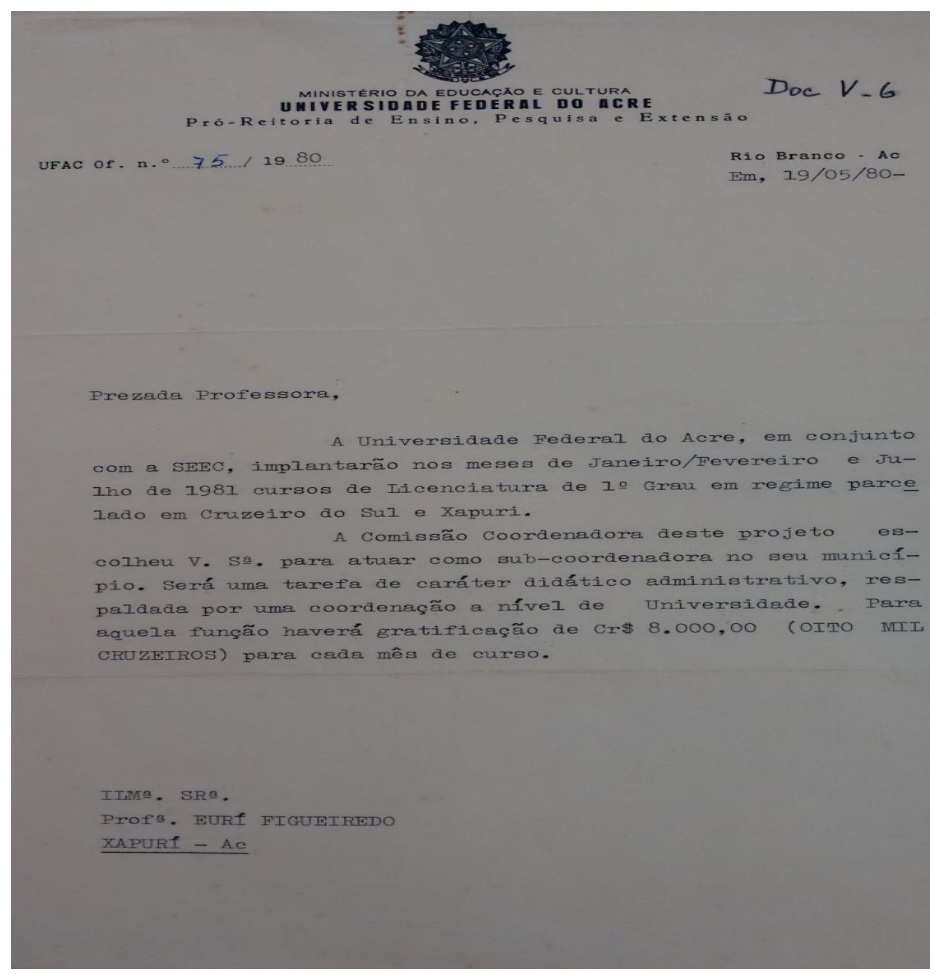

Fonte: Arquivo pessoal da professora.

Nesse período Coordenou o Curso para Professores Rurais, em nível de $1^{\circ}$ grau, qualificando-os para cursar o $2^{\circ}$ grau. Em 23 de outubro de 1984 aposentou-se por tempo de serviço do contrato de professora da União, quadro do magistério do extinto Território Federal do Acre. De 1985 a 1986 trabalhou como supervisora e orientadora de Língua Portuguesa nas escolas de $1^{\circ}$ e $2^{\circ}$ graus. Em 1996, encerrou sua carreira como docente aposentando-se também do contrato de professora da rede pública estadual de ensino, deixando seu legado marcado por quase meio século na vida daqueles que receberem seus ensinamentos.

\section{A tessitura da identidade profissional: na confluência da formação, das experiências e das práticas escolares}

No contexto das práticas e da trajetória profissional a professora Euri Figueiredo foi amealhando e semeando vivências e experiências que foram adquiridas desde os tempos de normalista no Colégio Divina Providência, a considerar que, no período compreendido entre os anos de 1952 a 1974 exerceu a função de professora, lotada nessa escola, instituição de ensino que existe até os dias atuais, lócus que marca

Rev. Caminhos da Educação: diálogos, culturas e diversidades, Teresina, v. 2, n. 2, p.140-160, mai./ago. 2020 
o início e parte do seu percurso e atividade na carreira do magistério. Neste estabelecimento escolar ministrou aulas nas disciplinas de Ciências, Anatomia, Geografia, Higiene, Comunicação e Expressão e Português.

Exerceu a função de Diretora na Escola Plácido de Castro no período de 1958 a 1961 e de 1964 a 1966 e, posteriormente veio a ocupar a mesma função na Escola de $1^{\circ}$ Grau Anthero Soares Bezerra no período de 1967 a 1970, seguido da Direção da Escola de $2^{\circ}$ Grau Padre Felipe Galerani (1977 a 1980), conforme podemos extrair da Portaria 130/80 - SEE. No período de 1977 e 1978 também dirigiu a escola de $1^{\circ}$ Grau Divina Providência. No período de 20 de fevereiro de 1958 a 31 de dezembro de 1961, 04 de março de 1964, 31 de dezembro de 1966 assumiu a Secretaria do Grupo Escolar Plácido de Castro, 12 de fevereiro e 06 de maio de 1970 na escola de primeiro grau Anthero Soares Bezerra.

No ano de 1981 ministrou aulas na Escola de $2^{\circ}$ Grau Padre Felipe Galerani, lecionando a disciplina de Literatura Brasileira. O manuseio de alguns documentos disponibilizados pela professora nos permite identificar e evidenciar que embora tenha exercido de forma recorrente o cargo de Diretora de Escola, a professora sempre manteve seu vínculo e atuação com a sala de aula.

Com o objetivo de resgatarmos lembranças da trajetória profissional e da formação escolar assim como elementos que nos permitissem traçar como se deu o desenvolvimento de suas atividades laborais, apresenta-se, na sequência, questões diretamente ligadas as domínio da atuação profissional, da experiências e das práticas pedagógicas, da constituição e desenvolvimento profissional na perspectiva de abordar sua trajetória, visando ressaltar suas contribuições no desenvolvimento da educação pública no município de Xapuri.

Assim, obtivemos informações que demonstraram como se deu sua formação no Magistério e na Educação Superior à medida que recupera algumas lembranças da escola e da formação escolar recebida e pontua algumas influências na imersão deste percurso de formação e de aprendizagem para o desenvolvimento da profissão.

A Professora Raimunda Euri Gomes Figueiredo, é popular e carinhosamente conhecida como Professora Euri, tem 87 anos, viúva, Licenciada em Letras, começou a aturar no magistério no ano de 1952. Pelo que nos relatou, trabalhou 32 anos pela

Rev. Caminhos da Educação: diálogos, culturas e diversidades, Teresina, v. 2, n. 2, p.140-160, mai./ago. 2020 
União e 8 anos pelo Estado, exercendo funções que vão da docência, passando pela a direção à supervisão em escolas públicas do município, até o ano de 1996.

Destacamos, a seguir, um trecho da fala em a professora rememora sua vinda do seringal para a cidade e o seu ingresso na escola:

\begin{abstract}
"Quando vim do seringal com meu pai, tinha nove anos de idade, por volta de 1939. Sempre fiquei no colégio das freiras. Fiz o primário de antigamente, e em seguida, as irmãs lutavam para fazer um curso mais adiantado, conseguiram um curso até a $5^{a}$ série, não se contentaram e fundaram a Escola Normal. Havia carência de professores, realizaram uma prova entre os alunos da $5^{\mathrm{a}}$ série no mês de abril do ano de 1944 . Desses alunos passaram apenas cinco, fui selecionada. A partir de então começou a escola normal. Uma das exigências seria a criação de uma escola que tivesse ligação com 0 meio, a vegetação, o plantio e que pudesse favorecer as alunas que vinham do interior, então passou a ser escola rural normal. Tínhamos um Prefeito, que era formado em Agronomia que se empenhou muito nesse projeto, foi o Francisco Coelho e aí nós começamos e continuamos os estudos".
\end{abstract}

Em suas narrativas nos relatou que sua primeira experiência profissional no magistério se deu aos dezesseis anos, no ano de 1948, e que começou a atuar como professora porque uma das alunas casou e o marido não consentiu que ela continuasse a lecionar. A freira diretora, então, pediu para que essa aluna indicasse alguém. Seu nome foi indicado sem que ela soubesse:

"[...] iniciei minha missão de professora dando aulas de Geografia e História, depois inclui Ciências, Higiene e Puericultura, Anatomia Humana e Português mais tarde. Nunca quis ser somente dona de casa, achava um trabalho rotineiro e angustiante. Começaram a fundar a escola normal, já com outras características e comecei a estudar novamente, dava aulas e estudava na escola normal porque faltava professor, sendo obrigada pela irmã Petronília Trinca a fazer mesmo não me sentindo capacitada por não dominar a disciplina de História".

Face à sua identificação com o magistério e considerando algumas das experiências como professora na Escola Normal, prestou concurso vestibular e ingressou no Curso de Letras/Português da Universidade Federal do Acre.

"Fiz o vestibular e fui escolhida para fazer letras porque faltava professor de Português, a faculdade era em regime parcelado, primeiro de curta duração, depois três períodos de especialização até concluir a plena".

Rev. Caminhos da Educação: diálogos, culturas e diversidades, Teresina, v. 2, n. 2, p.140-160, mai./ago. 2020 
Relatou-nos que a opção pelo Curso de Letras/Português deveu-se ao fato de não se identificar com a disciplina que estava a lecionar, que era História, à época da realização do concurso vestibular em Xapuri. Assim ela descreve este momento:

"Comecei a dar aula de geografia, história, depois incluí ciências, higiene pueril, cultura e anatomia humana. Pela falta de professores passei a ministrar aulas de Português. Começaram a fundar a escola normal aqui, agora com outras características foi quando comecei a estudar novamente, dava aula e estudava na escola normal porque faltava professor, mesmo não me sentindo capacitada por não dominar a disciplina de História, a irmã me obrigou a dar aulas. Uma colega me dava muitas dicas, compartilhava suas experiências sobre História e muitas aulas e tudo, e assim eu dava aula. Até que eu fiz o vestibular e fui escolhida pra fazer letras porque faltou professor de Português lá e a irmã me colocava para substitui-lo, como eu tinha sido uma aluna, uma ex- aluna desde pequena, ela tinha um alto domínio sobre mim e dizia: não você vai, mas não tem jeito você tem que ir, então eu ficava com aquela disciplina. Com isso eu ia estudar feito louca pra puder dar conta da disciplina que eu queria lecionar afinal, e assim fui. Depois fiz letras, consegui o vestibular e fiz a faculdade em regime parcelado, primeiro de curta duração, depois três períodos de especialização até concluir a plena e por ai eu fiquei".

Sobre a Graduação em Letras na UFAC a professora relembra que:

"Encontrei algumas dificuldades, pois era um curso intensivo, saíamos no começo de janeiro e voltávamos entre os meados de março para casa. Deixava a família e ia para Rio Branco, sem alojamento próprio e alimentação, depois de algum tempo começamos a receber uma bolsa alimentação destinada a todos alunos do interior, eram três cursos: Letras, Estudos Sociais (geografia e história), e Matemática, Pedagogia veio bem depois. Tivemos que fazer dois anos para que se tornasse plena também parcelado, pois era de curta duração e complementamos em Brasiléia para adquirir a Plena".

A conclusão da Graduação em Letras se concretizou no ano de 1993, obtendo o título de Licenciada em Letras Português com habilitação em Língua Portuguesa e suas respectivas Literaturas. Em relação às influências e lembranças do período em que realizou seu curso de graduação, a professora relembrou que recebeu apoio da família e o incentivo dos demais colegas de profissão.

Rev. Caminhos da Educação: diálogos, culturas e diversidades, Teresina, v. 2, n. 2, p.140-160, mai./ago. 2020 
Figura 7 - Diploma Graduação em Licenciatura em Letras

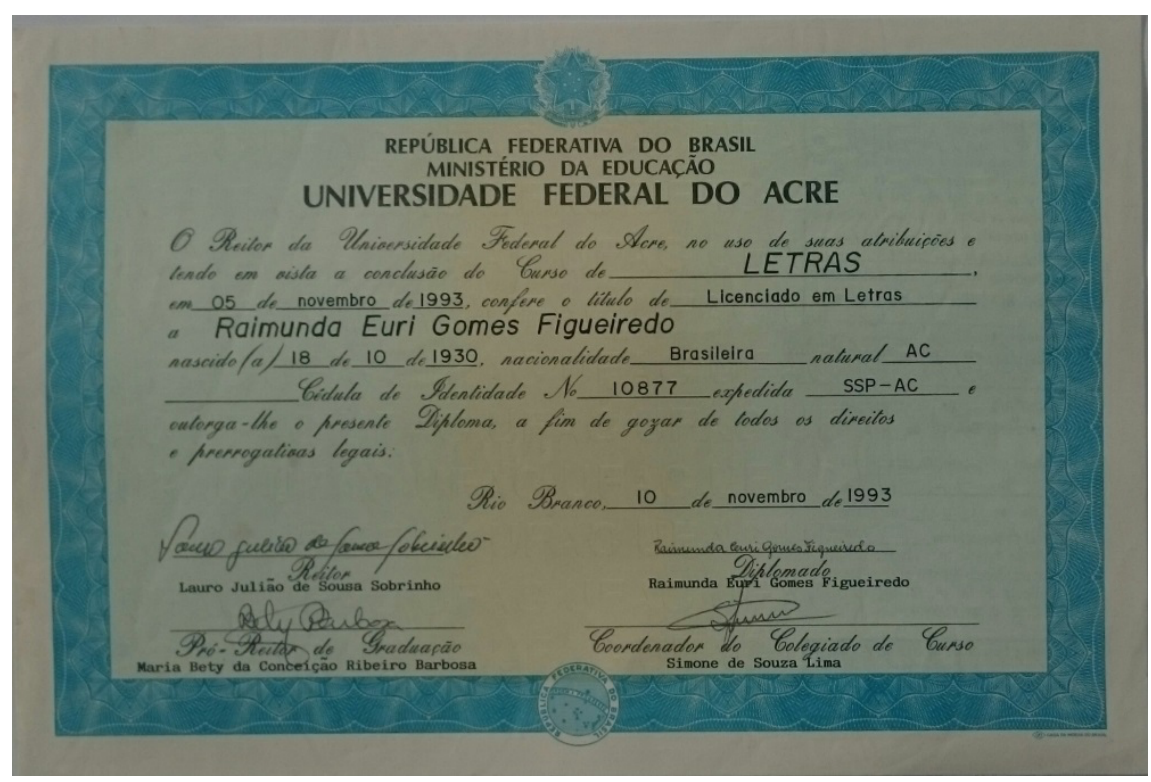

Fonte: Arquivo pessoal da professora.

Dos depoimentos da professora foi possível identificarmos que sua primeira experiência profissional no magistério se deu concomitante à formação na Escola Normal em substituição a uma outra professora. Ao ser indagada sobre o seu processo de constituição e desenvolvimento profissional diz que:

\begin{abstract}
"Em primeiro lugar, com a experiência e por gostar de dar aula, porque também tive bons professores e metodologias. Depois que fiz letras melhorou muito meus conhecimentos, me despertou também pra novas experiências mais sólidas, confiantes. Dávamos aula pela força de vontade mesmo e nessa época saíam daqui alunos bem preparados, chegavam a Rio Branco e eram aprovados no vestibular, que antigamente era um "bicho de sete cabeças" pra passar não era brincadeira. Outros iam para o Rio de Janeiro e Belém fazer um curso de Medicina, de Engenharia, aqueles que os pais tinham mais recursos, e nunca nos envergonharam, por isso que chamavam aqui a "Capital Cívica do Acre" era porque as irmãs também davam uma formação muito boa as "Servas de Maria", nós recebemos ensinamentos muito bons. Era uma rigidez às vezes exagerada, mas que serviram muito pra nossa vida, não me queixo de toda a formação que eu tive desde nove anos com as freiras, pra passar de classe era uma exigência tremenda, pra mim valeu a pena, era uma escola que dava uma formação geral".
\end{abstract}

Em se tratando dos diferentes estágios de atuação, as diferenças, mudanças e alterações em sua prática profissional a professora diz:
"Pedi minha aposentadoria um pouco antes do tempo, comecei sentir uma falta de apoio, um relaxamento, quase um faz de conta, nós não vamos questionar, nós não podemos fazer isso e aquilo começou a me ferir, eu acho que a gente tem que ter seriedade no trabalho. Essas coisas foram me deixando nervosa, me decepcionando e comecei a me

Rev. Caminhos da Educação: diálogos, culturas e diversidades, Teresina, v. 2, n. 2, p.140-160, mai./ago. 2020 
sentir fragilizada, ficava sem o apoio necessário pra fazer como eu gosto de fazer, como queria fazer, como sempre fiz. por isso, deixei de dar aula. Eu disse: em sala de aula não fico mais, pois não vou ficar numa sala de aula onde não posso dizer que 0 aluno tem que prestar atenção, não é em mim é na aula, eu acho que se ele veio necessitando da aula, ele teria que prestar atenção. Sentia que era só se o aluno quisesse".

Em seu depoimento diz que o pedido de aposentadoria do magistério se deveu a dois fatores: a perda da autonomia do professor e o agravamento do estado de saúde do seu esposo.

A professora foi bastante atuante na educação municipal e ao tratar da fundação da escola Anthero Soares Bezerra, hoje umas das principais escolas do Município, relembrou:

\begin{abstract}
"Foi muito difícil conseguir apoio do governo para a fundação da Escola Anthero Soares Bezerra, disse que não tinha condição e perguntou com qual autorização eu havia fundado a escola e que eu ficaria responsável pelo pagamento dos professores. Eu disse a ele que não tinha condições e que só sairia dali quando o mesmo me desse um documento relatando que não se responsabilizaria e que eu tenho que terminar com a escola, pois quero da uma satisfação para os alunos e professores que trabalharam o ano inteiro sem receberem nada por isso. O Governo ficou espantado, chamou a secretária e nos deu condições para continuamos com a construção com muito trabalho. De fato, foi um abuso meu começar uma escola juntamente com alguns professores, porém víamos além da necessidade, a empolgação dos colegas e da primeira turma por conseguirmos um local próprio para estudar. Chorei de alegria porque valeu apena, hoje é uma grande escola que atende muitos alunos."
\end{abstract}

$\mathrm{Na}$ Escola Anthero Soares Bezerra, a professora Euri Figueiredo assumiu a direção no período de 1967 a 1970. A escola representava para a professora palco de lutas pela educação na cidade em uma época que o Brasil passava pelo período do regime militar (1964 a1984) e o Estado do Acre, recém elevado à categoria de Unidade da Federação, por sua localização geográfica era visto como área de segurança nacional dentro da política do nacional desenvolvimentismo, experimentando no plano da política a nomeação de cargos dirigentes da política e da administração do Estado e dos municípios.

O Colégio Divina Providência grande parte de seu percurso de formação e atuação profissional, pois foi lá que tudo começou, todo o processo de desenvolvimento educacional, a construção profissional, social. Recordou a professora ser "muito grata pela educação rígida que recebi no colégio, pois me tornou uma pessoa preparada para o convívio social".

Rev. Caminhos da Educação: diálogos, culturas e diversidades, Teresina, v. 2, n. 2, p.140-160, mai./ago. 2020 
Nos anos de 1958 a 1961 assumiu, pela primeira vez, a direção do Grupo Escolar Plácido de Castro, período de transição em que o Acre deixaria de ser território e adquiria sua emancipação um ano após em 1962, ano em que também aconteceu a primeira eleição para governador no Acre.

$\mathrm{Na}$ UFAC, em 1980, foi coordenadora de cursos parcelados, sendo indicada pela Coordenação Geral da UFAC. Para a professora foi um momento de muita satisfação e logo vieram às lembranças do período em que ela mesma com tantas dificuldades faz o curso de Letras/Português, ofertado em regime parcelado pela UFAC na Cidade de Rio Branco (1975).

\section{Considerações finais}

Buscamos neste trabalho apresentar uma temática bastante recorrente no campo da formação de professores investigando como se deu o processo de constituição do "ser professor" de uma professora de destaque na educação do município de Xapuri-Ac. Para tanto, procuramos traçar os diferentes momentos e contextos que marcam sua trajetória escolar, suas diferentes experiências de formação e de atuação profissional que marcaram seu percurso e sua carreira no magistério.

A nossa interlocutora neste estudo é uma professora bastante conhecida em Xapuri, referenciada por suas contribuições à educação e um "espécie de memória" da educação do local haja vista ser egressa da primeira escola de Xapuri, o Colégio Divina Providência, da Escola Normal assumida pelas irmãs "Servas de Maria Reparadoras" em meados da década de 1940, espaço no qual enquanto se formava iniciou suas atividades laborais.

Com base na fundamentação teórica e por meio da entrevistas pudemos compreender que o processo de formação do professor não está baseado somente nas estratégias de ensino proposto pela instituição escolar e que todo professor precisa refletir sobre sua ação pedagógica trazendo consigo as experiências de suas relações e vivência nas demais dimensões da vida social. Assim sendo, destacamos aspectos que abrangem a formação, a carreira e o processo de desenvolvimento profissional no Magistério com destaque para a trajetória profissional da professora Raimunda Euri

Rev. Caminhos da Educação: diálogos, culturas e diversidades, Teresina, v. 2, n. 2, p.140-160, mai./ago. 2020 
Gomes Figueiredo, aspecto que nos permitiu reconhecer a importância da formação no desenvolvimento profissional docente.

O estudo permitiu-nos refletir sobre como o profissional do magistério se constitui no entrecruzamento da formação com a prática pedagógica, a experiência e os saberes que vão sendo construídos na ação pedagógica, ou seja, a formação profissional docente se dá em diferentes dimensões e contextos aspectos que reitera a compreensão de que o professor carrega consigo marcas de suas experiências vividas, dando suporte para desenvolver de forma individual e coletiva conhecimentos, saberes e práticas que irão compor o repertório dos conhecimentos que mobiliza quando de sua atuação e inserção no ofício de ensinar.

\section{Referências}

FIORENTINI, D. A pesquisa e as práticas de formação de professores de Matemática em face das políticas públicas no Brasil. Bolema - Unesp, Rio Claro, ano 21, n. 29, p. 43 -7 0, 2008.

LOURO, Guacira Lopes. Mulheres na sala de aula. In: DEL PRIORI Mary (Org.). História das mulheres no Brasil. 9. ed. São Paulo: Contexto, 2008.

NÓVOA, A. Notas sobre formação (contínua) de professores, 1994.

NÓVOA, A. Os professores e sua formação. Lisboa, Dom Quixote, 1992a.

NÓVOA, A. Vidas de professores. Porto, Porto Editora, 1992b.

NÓVOA, A. (org.). Profissão professor. Porto, Porto Editora, 1991.

NÓVOA, António. Vidas de professores. Edição/reimpressão, Porto Editora, 2007.

PERRENOUD, P. Práticas pedagógicas profissão docente e formação: perspectivas sociológicas. Lisboa: Dom Quixote, 1993.

PIMENTA, S.G. Formação de professores: Identidade e saberes da docência. In: PIMENTA, S.G. (Org.) Saberes pedagógicos e atividade docente. São Paulo: Cortez, 1999.

TARDIF, M. Saberes docentes e formação profissional. 2. ed. Petrópolis: Vozes, 2002.

TARDIF, Maurice. Saberes Docentes e Formação Profissional. 4. ed. Petrópolis, RJ: Vozes, 2004

TARDIF, Maurice. O trabalho docente, a pedagogia e o ensino. Interações humanas, tecnologias e dilemas. In: TARDIF, Maurice. Saberes docentes e formação profissional. 12. ed. Petrópolis, RJ: Vozes, 2011.

RECEBIDO: $1 / 05 / 2020$

APROVADO: $1 / 07 / 2020$

RECEIVED: $1 / 05 / 2020$

Rev. Caminhos da Educação: diálogos, culturas e diversidades, Teresina, v. 2, n. 2, p.140-160, mai./ago. 2020 
ENTRE MEMÓRIAS E HISTÓRIAS: a trajetória de formação e atuação profissional de uma professora acreana

APPROVED: $1 / 07 / 2020$

RECIBIDO: $1 / 05 / 2020$

APROBADO: $1 / 07 / 2020$

Rev. Caminhos da Educação: diálogos, culturas e diversidades, Teresina, v. 2, n. 2, p.140-160, mai./ago. 2020 